that the authors aro looking at their subject upsido down? Can it be that they are actually unaware of the basic importanee of genetics for their subject?"), but the fact is that the taxonomic implications of population genetics and associated disciplines cannot be appreciated without an understanding of what taxonomy is all about in the first place.

An admirable book, then, destined to become a standard text in its own special field. For the practising taxonomist it is cortainy obligate reading, whatever his prosent degree of enlightenment. From the non-taxonomic user of tho products of taxonomy it deserves serious attontion as a lucid and thoroughly documented treatmont of the purposes and philosophy of a discipline frequently misunderstood and ofton misrepresented. For the student concerned to know what taxonomy has to offer as a discipline, it provides a stimulating and challenging introduction and guide. In this last connexion, it is gratifying to know that the authors are oach to bo concorned with new postgraduate courses in taxonomy in their respective universities, Edinburgh and Liverpool; with this text, their students should have a flying start.

Production is excellent, and the price, especially of the paper-back version, low enough to ensure that the volume, massive though it is, will have the circulation it deserves.

J. HESLOP-HARRISON

\section{CLASSICAL PEDOLOGY}

Treatise on Soil Science

By K. D. Glinka. Fourth (posthumous) edition, revised by the soil scientists of the Dokuchaev Soil Institute, Academy of Sciences of the U.S.S.R. Translated from the Russian by Prof. A. Gourevitch. Pp. v+674. $126 s$.

\section{Chemical Analysis of Soils}

By K. K. Gedroits. Translated from the Russian by B. Toker and J. Schmorak. Pp. v+602. $126 s$.

(Jerusalem: Israel Program for Scientific Translations; London: Oldbourne Press, 1963.)

C LINKA'S Treatise on Soil Science is one of the classics $\checkmark$ in the literature of pedology, and as such its translation into English must be welcomed.

Bibliographical and other material omitted from the third edition was restored in the latest Russian edition, but even so, such references as "cf. objections by Borggreve, by Wollny, by Dokuchaev" are common, and the book suffers from the incomplete documentation so common in Russian works on soil science.

The fourth edition was published in 1931-about the time that the application of X-ray diffraction to the investigation of soils overthrew many of the views then held in soil science; it follows that the first half of the book, which deals with "Soil Formation and General Properties of Soils", has little more than historical interest to-day. The chief value of the book lies in the section on "Soil Types and Soil Geography", which contains definitive descriptions of the great world groups.

Glinka makes no concessions to the novice; names of soil types are introduced without definition, and even in the chapter devoted to a particular soil type it is usually nocossary to read most of the chapter before finding a passing reference to the soil's distinguishing characteristics. As in much present-day literature on soil, most of the information is given in the form of profile descriptions, which even dedicated specialists appear to find hard to follow. It would be a great help to the reader if a statement of the significant features of a profile were appended.

Glinka's essentially descriptive approach to the subject is exemplified by the statement on p. 170 "... one should not forget that the main task resides in the eluci- dation of the process which resulted in the formation of any given soil type...". One can only commend this, but the paragraph continuos: "Laboratory research should be carried out in such a way as to disclose the loss and gains of each of the several horizons ... each and every horizon in the soil profile must be studied separately and its properties compared with those of the parent rock". Laboratory research is thus eonsidered as no more than the detection of gains and losses, but the fact remains that one has done no more than define the problem by establishing that translocation has occurred. It is no criticism of Glinka's book to say that at present we must ask how and why translocation takes place; when we ask this question, the extent of our ignorance of soil genetics is all too apparent.

Just as in the development of the older sciences, pedology has reached the stage at which the descriptive approach initiated by Dokuchaev, and developed so ably by the Russian school, needs to be supplemented by experimental investigation of the fundamentals of soil-forming processes.

Units are often omitted from tables of analytical data, and the basis on which percentages are calculated is not always specified. The table on p. 142 contains a typographical error carried over from the Russian edition. as well as several minor errors in calculation. The translator directs attention to several similar errors in the Russian version.

Despite a slightly un-English syntax the translation reads smoothly, although the word 'chemism', which is used throughout the book, caused some hesitation; it seems to mean "chemical composition-cum-chomical properties". Misprints are few and, with the exception of the omission of the latter part of a sentence on p. 402, do not obseure the meaning.

Gedroits's Chemical Analysis of Soils must have been a very good book in 1932 when it was last re-edited but its value to-day is questionable. About one-third of the book consists of a supplement of newer methods compiled after the death of Gedroits, and which gives references up to about 1953. However, apart from descriptions of the use of some Russian optical equipment, the supplement contains little that is not already available in the literature.

Gedroits's original section is characterized by an extremely thoughtful approach and he emphasizes the need for selecting the method most appropriate for the particular purpose. For this reason the book has some value as background reading but it is unlikely to find much use on the bench of the practising analyst.

\section{Bloomfield}

\section{PHARMACEUTICAL ANALYSIS}

The Quantitative Analysis of Drugs

By Dr. D. C. Garratt, assisted by Dr. L. Brealey, C. A. Johnson, K. L. Smith and G. Sykes. Third edition. Pp. xiii +925. (London: Chapman and Hall, Ltd., 1964.) 126s. not.

THE appearance of a revised edition of this hardy 1 perennial of the analytical field is an event that will be welcomed by all practising pharmaceutical analysts. On this occasion Dr. Garratt has been assisted in the marathon task by a team of specialist colleagues and the result is one that must bring satisfaction to readers and authors alike. The last revision of the book appeared in 1955 , and the fact that the authors have found it necessary to increase the size of the present volume by some 250 pages reflects the rapid growth in complexity of the subject over this period.

The manner of presentation of material remains the same as in previous editions. Drugs are dealt with by means of monographs arranged in alphabetical order, 